'Facultad de Ciencias de la Salud, Escuela de Odontología, Universidad Autónoma de Chile. Santiago, Chile. ${ }^{2}$ Facultad de Medicina, Escuela de Odontología, Pontificia Universidad Católica de Chile. Santiago, Chile. ${ }^{3}$ Instituto de Ciencias Biomédicas, Facultad de Ciencias de la Salud, Universidad Autónoma de Chile. Santiago, Chile.

aEstudiante de Odontología. ${ }^{b}$ Cirujano Dentista especialización en Imagenología Oral y Maxilofacial.

Ingeniero en Biotecnología Molecula. PhD.

Apoyo financiero: Sociedad Científica de Estudiantes Universidad Autónoma de Chile (subsidio de investigación), Beca iniciación científica.

Recibido el 7 de abril de 2020 aceptado el 6 de agosto de 2020 .

Correspondencia a:

Gilena Cruzat Villalobos.

Dirección: Avenida Vital

Apoquindo 1690, Block C-17, Departamento 404, Las Condes, Santiago.

gilena.cruzat@hotmail.com

\section{SARS-CoV-2 en atención odontológica: vías de transmisión y sus consideraciones en la práctica clínica}

\author{
GILENA CRUZAT VILLALOBOS ${ }^{1, a}$, FELIPE BARRERA G. ${ }^{2, b}$, \\ LORETO F. FUENZALIDA ${ }^{3, c}$
}

\section{Dental care during SARS-CoV-2 pandemic}

We analyze the transmission routes, possible viral reservoirs in the oral cavity and considerations about dental care of SARS-CoV-2 virus infection. We also analyze the protocols required before and after a dental procedure, aiming to increase the awareness of dentists about the importance of virus spread prevention among health care workers and patients. The evaluation of symptoms associated with SARS-CoV-2 such as fever, fatigue, dry cough, myalgia, dyspnea, and the inquiry about possible contacts with infected people is of utmost importance. The tongue and oral mucosa are important viral reservoirs and the transmission of the virus occurs primarily by saliva droplets. Therefore, elective dental care should be postponed, attending only dental emergencies during this period, incorporating the use of protective personal equipment (PPE) and using manual instruments to prevent the production of aerosols.

(Rev Med Chile 2020; 148: 1302-1306)

Key words: Coronavirus; Dentistry; Dental Care; SARS-CoV-2.
$\mathrm{E}$ 1 siguiente trabajo expone consideraciones en el contexto de la pandemia de SARSCoV-2 (severe acute respiratory syndrome coronavirus 2), promoviendo la disminución del riesgo en la exposición al virus para el profesional odontólogo y usuarios.

En el mes de diciembre del año 2019, ocurrieron una serie de casos de neumonía en la ciudad de Wuhan, China. El origen de esta enfermedad fue atribuido a un nuevo coronavirus, denominado SARS-CoV-2, inicialmente de transmisión animal-humano, que tuvo su foco en el mercado mayorista de mariscos de Wuhan, provincia de Hubei, China. El huésped natural de SARS-CoV-2 puede ser el murciélago Rhinolophus affinis, ya que SARS-CoV-2 mostró 96,2\% de la identidad del genoma completo al coronavirus que infecta a murciélago BatCoV RaTG13 ${ }^{1}$. Los síntomas que presentaban estos pacientes fueron fiebre, fatiga, tos seca, mialgia y disnea. Además, algunos sufrían de dolor de cabeza, mareos, dolor abdominal, diarrea, náuseas y vómitos. El inicio de la enfermedad puede conducir a insuficiencia respiratoria progresiva, debido al daño alveolar, e incluso a la muerte.

Oficialmente, el día 8 de enero de 2020, el Centro Chino para el Control y Prevención de Enfermedades reconoce a SARS-CoV-2 como una nueva cepa de coronavirus y ya en marzo, la infección por SARS-CoV-2 fue confirmado como pandemia por la Organización Mundial de la Salud (OMS). El número cada vez mayor de casos y la evidencia de transmisión de persona a persona sugirieron que el virus era más contagioso que la influenza y el MERS-CoV².

El primer caso de un paciente infectado por SARS-CoV-2 en Chile fue identificado el día 3 de marzo de 2020, decretándose Fase 1 de la pandemia y pasando, rápidamente a Fase 4 o de transmisión sostenida debido al crecimiento exponencial del SARS-CoV-2 del número de contagiados. Al 24 de julio de 2020 Chile contaba con 250.767 


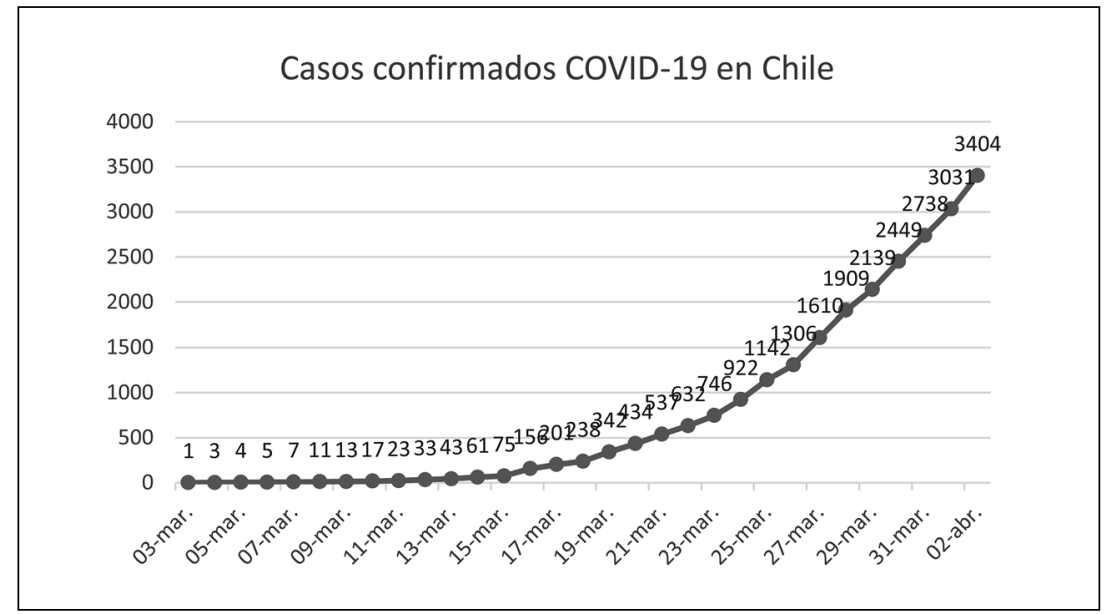

Figura 1. Curva que muestra el número de contagiados desde el 3 de marzo de 2020 al 2 de abril del mismo año. Datos obtenidos del Ministerio de Salud de Chile. casos confirmados acumulados y 4.505 personas fallecidas $^{3}$ (Figura 1).

\section{Expresión de ACE2 en tejidos orales}

Zhou y cols ${ }^{4}$ señalan que el virus es diferente del SARS-CoV que circuló el año 2002, pero comparten el mismo receptor celular, la enzima convertidora de angiotensina humana 2 (ACE2). SARS-CoV-2 ingresa a las células huésped a través del receptor de células humanas ACE2, pero con una mayor afinidad de unión que SARS-CoV ${ }^{5}$. Por otra parte, $\mathrm{Xu}$ y cols. ${ }^{6}$ mostraron que la mucosa de la cavidad oral podía expresar niveles no menores de la proteína ACE2, presentando mayor expresión en la lengua que otros sitios orales. Curiosamente, encontraron que ACE2 también se expresa en linfocitos dentro de la mucosa oral, aunque la proporción de linfocitos positivos para ACE2 fue bastante pequeña.

Estos hallazgos preliminares han hecho comprender que la cavidad oral tiene un riesgo potencialmente alto para la susceptibilidad infecciosa de SARS-CoV-2 y proporcionan una evidencia para la futura estrategia de prevención en la práctica clínica, así como en la vida diaria.

\section{Vías de transmisión y contagio en la consulta dental}

La transmisión de persona a persona del virus sería de manera directa, por tos, estornudos, inha- lación de gotas, contacto con las mucosas orales, nasales y oculares. Igualmente, este se podría transmitir por la saliva y deposiciones fecales ${ }^{1}$.

Respecto a los odontólogos, en la práctica dental se exponen a casi la mayoría de los medios de contacto, siendo uno de los agentes de salud más afectados, ya que se trabaja a menos de 30 $\mathrm{cm}$ de la persona, con mucosas, sangre, saliva, otros fluidos corporales y el manejo de instrumental afilado.

Los microorganismos patógenos pueden transmitirse en entornos dentales a través de la inhalación de microorganismos transportados por el aire que pueden permanecer suspendidos durante largos períodos, por contacto directo con sangre, fluidos orales $u$ otros materiales del paciente. Además, existen otras formas de contagio para el odontólogo y los usuarios, tales como el contacto de la mucosa conjuntival o nasal con gotas y aerosoles que contienen microorganismos generados a partir de un individuo infectado y propulsados a corta distancia, tosiendo o hablando sin mascarilla y el contacto indirecto con instrumentos contaminados o superficies ambientales ${ }^{1}$.

La transmisión de gotitas y aerosoles que contengan SARS-CoV-2 son una de las preocupaciones más importantes en clínicas y hospitales, dado que es difícil evitar la generación de grandes cantidades de aerosoles y gotitas mezcladas con la saliva del paciente e incluso sangre durante la práctica dental. Por ejemplo, la turbina utiliza agua para permitir que la fresa se refrigere cuando gira a alta 
velocidad. Las partículas de gotas y aerosoles son lo suficientemente pequeñas como para permanecer en el aire durante un período prolongado antes de que se depositen en las superficies ambientales o ingresen al tracto respiratorio. Estudios recientes muestran que SARS-CoV-2 puede permanecer viable hasta por $3 \mathrm{~h}$ en aerosoles ${ }^{7}$.

Además, los coronavirus humanos como el SARS-CoV, el coronavirus del síndrome respiratorio del Medio Oriente (MERS-CoV) o los coronavirus humanos endémicos $(\mathrm{HCoV})$ pueden persistir en superficies como metal, vidrio o plástico durante un par de días; además, a temperatura ambiente, el $\mathrm{HCoV}$ permanece infeccioso desde 2 h hasta 9 días, y si consideramos la humedad, persiste mejor a $50 \%$ en comparación con $30 \%$ de humedad relativa. Por lo tanto, mantener un ambiente limpio y seco en el consultorio dental ayudaría a disminuir la persistencia de SARS$\mathrm{CoV}-2^{1}$.

\section{Consideraciones en la atención odontológica}

La atención en el contexto de pandemia debe ser solo de carácter de urgencias dentales, que según el libro del Ministerio de Salud "Urgencias Odontológicas Ambulatorias" serían pericoronaritis, patología pulpar inflamatoria, infecciones odontogénicas, gingivitis ulcero-necrotizante, trauma dentoalveolar y complicaciones posterior a exodoncia ${ }^{8}$.

\section{Protocolo de detección y diagnóstico}

La temperatura corporal del paciente debe medirse en primer lugar. Se recomienda un termómetro de frente sin contacto para el examen. Se debe usar un cuestionario para evaluar a los pacientes con posible infección de SARS-CoV-2 antes de que puedan ser conducidos al lado del sillón dental. Estas preguntas deben incluir lo siguiente:

- ¿Tiene fiebre o ha tenido fiebre en los últimos 14 días?

- ¿Ha experimentado un inicio reciente de problemas respiratorios, como tos o dificultad para respirar en los últimos 14 días?

- ¿Ha viajado en los últimos 14 días al extranjero o ha visitado algún vecindario con alta tasa de transmisión documentada de SARS-CoV-2?

- ¿Ha entrado en contacto con un paciente con infección confirmada por SARS-CoV-2 en los últimos 14 días?
- ¿Ha entrado en contacto con personas con fiebre reciente o problemas respiratorios documentados en los últimos 14 días?

- ¿Ha participado recientemente en alguna reunión, o ha tenido contacto cercano con muchas personas desconocidas?

Es importante señalar que estas preguntas indagatorias deben ser elaboradas de acuerdo con el contexto geográfico de transmisión.

Si un paciente responde "sí" a cualquiera de las preguntas de detección, y su temperatura corporal es inferior a $37,3^{\circ} \mathrm{C}$, el dentista puede diferir el tratamiento hasta 14 días después del evento de exposición. Se debe instruir al paciente para que se ponga en cuarentena en el hogar e informe cualquier experiencia de fiebre o síntomas similares a la gripe al departamento de salud local. Si un paciente responde "sí" a cualquiera de las preguntas de detección, y su temperatura corporal es igual o superior a $37,3{ }^{\circ} \mathrm{C}$, el paciente debe ser puesto en cuarentena de inmediato, y los dentistas deben informar al departamento de control de infecciones del servicio de salud. Si un paciente responde "no" a todas las preguntas de detección, y su temperatura corporal es inferior a $37,3^{\circ} \mathrm{C}$, el dentista puede tratar al paciente con medidas de protección adicionales y evitar los procedimientos de salpicadura o de generación de aerosoles al máximo. Si un paciente responde "no" a todas las preguntas de detección, pero su temperatura corporal no es inferior a $37,3^{\circ} \mathrm{C}$, el paciente debe recibir instrucciones para recibir atención médica adicional por posible contagio por SARS-CoV-2.

\section{Protocolos sanitarios}

Los odontólogos deben lavarse las manos y antebrazos con agua y jabón antes del examen del paciente, antes de los procedimientos dentales, después de tocar al paciente, después de tocar el entorno y el equipo sin desinfección, y después de tocar la mucosa oral, la piel o herida dañada, la sangre, el fluido corporal, la secreción, y excreta. Se debe tener más precaución para que los odontólogos eviten tocarse sus propios ojos, boca y nariz. Se debe usar elementos de protección personal (EPP) que incluye gafas protectoras, máscaras, guantes, gorras, protectores faciales y ropa protectora durante toda la atención médica. 


\section{Utilización de enjuague bucal antes de procedimientos dentales}

En general, se cree que un enjuague bucal antimicrobiano preoperatorio reduce la carga de microbios orales. Sin embargo, la clorhexidina, que se usa comúnmente como enjuague bucal en la práctica dental, ha demostrado no ser efectiva para eliminar al SARS-CoV-2 ${ }^{9}$. Dado que el virus es vulnerable a la oxidación, se recomienda el enjuague bucal preprocedimiento que contiene agentes oxidantes como peróxido de hidrógeno a $1 \%$ o povidona a $0,2 \%$, con el fin de reducir la carga salival del virus. Un enjuague bucal preprocedimiento sería más útil en los casos en que no se pueda usar una goma dique como aislamiento absoluto. De la misma forma, se recomienda instrumental manual, como carisolv y jackettes/ curetas, para la eliminación de caries y tratamiento periodontal, a fin de minimizar la generación de aerosoles tanto como sea posible ${ }^{1}$.

\section{Desinfección de la clínica}

Las instituciones médicas deben tomar medidas de desinfección efectivas y estrictas, tanto en entornos clínicos como en áreas públicas. La configuración de la clínica debe limpiarse y desinfectarse de acuerdo con el protocolo para la gestión de la limpieza y desinfección de superficies del entorno médico (WS / T 512-2016) publicado por la Comisión Nacional de Salud de la República Popular de China ${ }^{1}$.

Los desechos médicos (incluido el equipo de protección desechable después del uso) deben transportarse a tiempo al área de almacenamiento temporal del instituto médico. El instrumento y los artículos reutilizables deben tratarse previamente, limpiarse, esterilizarse y almacenarse adecuadamente de acuerdo con el Reglamento Sobre Manejo de Residuos de Establecimientos de Atención de Salud (REAS), del Ministerio de Salud ${ }^{10}$. Los desechos médicos y domésticos generados por el tratamiento de pacientes con infección sospechada o confirmada de SARS-CoV-2 se consideran desechos médicos infecciosos. Se deben usar bolsas de paquete de desechos médicos de color amarillo de doble capa y ligadura de "cuello de cisne". La superficie de las bolsas del paquete debe marcarse y desecharse de acuerdo con los requisitos para el manejo de desechos médicos ${ }^{1}$.

\section{Conclusiones}

SARS-CoV-2 es un virus altamente contagioso, presentando un desafío para las autoridades de salud de todo el mundo, puesto que no existía registro de él en la historia de la humanidad. Debido a esto, los alcances del contagio, su tratamiento y posibles curas están siendo investigadas en el seno de la pandemia.

En el contexto de pandemia, en cada urgencia dental, es imprescindible la evaluación de síntomas asociados a SARS-Cov-2 como fiebre, fatiga, tos seca, mialgia y disnea, además de investigar si ha estado en contacto con algún paciente positivo para el virus o ha realizado viaje a un lugar con transmisión documentada del virus.

Para la práctica odontológica, representa una complejidad la atención de pacientes debido a que la transmisión del virus es principalmente a través de gotitas de saliva. Reservorios importantes son la lengua y las mucosas de la cavidad oral, situándonos en un escenario extremadamente adverso. Por esto mismo, se debe comprender el principio de universalidad en todos los pacientes atendidos en la urgencia dental. La atención dental electiva debiera diferirse, atendiéndose en este periodo solo urgencias dentales, recomendándose el uso de instrumental manual para evitar la producción de aerosoles donde el virus logra permanecer estable por horas, así como el uso de EPP en cada atención.

Agradecimientos: Beca Iniciación Científica, Vicerrectoría de Investigación y Postgrado, Universidad Autónoma de Chile. Sociedad de Científica de Estudiantes de Odontología de la Universidad Autónoma de Chile.

\section{Referencias}

1. Peng X, Xu X, Li Y, Cheng L, Zhou X, Ren B. Transmission routes of $2019-\mathrm{nCoV}$ and controls in dental practice. Int J Oral Sci 2020; 12 (1): 9.

2. Zhao S, Lin Q, Ran J, Musa S, Yang G, Wang W, et al. Preliminary estimation of the basic reproduction number of novel coronavirus (2019-nCoV) in China, from 2019 to 2020: A data-driven analysis in the early phase of the outbreak. Int J Infect Dis 2020; 92: 214-7.

3. Casos confirmados en Chile COVID-19. Ministerio de Salud - Gobierno de Chile. Disponible en: https://www. 
minsal.cl/nuevo-coronavirus-2019-ncov/casos-confirmados-en-chile-covid-19/ [Consultado el 1 de abril de 2020].

4. Zhou P, Yang X, Wang X, Hu B, Zhang L, Zhang W, et al. A pneumonia outbreak associated with a new coronavirus of probable bat origin. Nature 2020; 579 (7798): 270-3.

5. Wrapp D, Wang N, Corbett K, Goldsmith J, Hsieh C, Abiona O, et al. Cryo-EM structure of the 2019-nCoV spike in the prefusion conformation. Science 2020; 367 (6483): 1260-3.

6. Xu H, Zhong L, Deng J, Peng J, Dan H, Zeng X, et al. High expression of ACE2 receptor of 2019-nCoV on the epithelial cells of oral mucosa. Int J Oral Sci 2020; 12 (1).

7. Van Doremalen N, Bushmaker T, Morris DH, Holbrook MG, Gamble A, Williamson BN, et al. Aerosol and
Surface Stability of SARS-CoV-2 as Compared with SARS-CoV-1. N Engl J Med 2020; 382: 1564-7.

8. Ministerio de Salud. Guía Clínica Auge Urgencias Odontológicas Ambulatorias. Santiago; 2011. Disponible en: http://www.repositoriodigital.minsal.cl/bitstream/handle/2015/495/Urgencias-Odontol\%c3\%b3gicas-Ambulatorias-2011.pdf? sequence $=1$ \&isAllowed $=\mathrm{y}$ [Consultado el 1 de abril de 2020].

9. Kampf G, Todt D, Pfaender S, Steinmann E. Persistence of coronaviruses on inanimate surfaces and their inactivation with biocidal agents. J Hosp Infect 2020; 104 (3): 246-51.

10. Ministerio de Salud. Reglamento sobre manejo de Residuos de Establecimientos de Salud. Santiago; 2009. Disponible en: https://www.minsal.cl/sites/default/files/ files/REAS.pdf [Consultado el 1 de abril de 2020]. 